\title{
LAS CARGAS PROBATORIAS DINÁMICAS
}

\author{
CRISTINA SANTIBÁÑEZ BORIC \\ Universidad de Chile
}

\begin{abstract}
RESUMEN: Las "cargas dinámicas", norma especial sobre la carga de la prueba contemplada en el artículo 493 del Código del Trabajo, buscan facilitar la prueba del trabajador denunciante en el procedimiento de tutela laboral. En este trabajo se analiza esta novedosa institución y se presentan algunas interrogantes que surgen de la misma, desde la perspectiva del derecho al debido proceso del empleador-denunciado. Dichas problemáticas se refieren a si existe aligeramiento probatorio o inversión de la carga de la prueba, cuál es el alcance de los "indicios suficientes" que exige el legislador y la necesidad de advertir al denunciado del aligeramiento probatorio.
\end{abstract}

Palabras clave: Cargas probatorias dinámicas, onus probandi, indicios suficientes, debido proceso.

ABSTRACT: The "dynamic loads", special rules concerning the burden of the proof required under Article 493 of the Labor Code, seeks to facilitate the proof by the claimant worker in the process of labor protection. This paper examines this new institution and presents some questions that arise from the standpoint of employer-defendant's due process rights. These issues relate to whether there is lightening of the evidence process or burden of proof inversion, what is the scope of "sufficient evidence" that requires the legislator and the need to warn the defendant of the lightening of the evidence.

Key words: Dynamic loads, onus probandi, sufficient evidence, due process.

\section{INTRODUCCIÓN}

En virtud de la Ley $N^{\circ}$ 20.087, que modificó el Libro V del Código del Trabajo, se introdujo en nuestro ordenamiento un nuevo procedimiento, denominado de Tutela Laboral, cuyo objeto es otorgar la debida protección de los derechos fundamentales de los trabajadores en el seno de las relaciones laborales.

Dicho procedimiento contempla una norma especial relativa a la carga de la prueba, la que se conoce como cargas dinámicas. Esta institución constituye una novedad no solo dentro del procedimiento laboral, sino que en nuestro ordenamiento jurídico en general, toda vez que no existe ninguna norma que se le asemeje. Sin embargo, esta institución, que busca facilitar la prueba del trabajador denunciante, en la forma en que fue concebida por nuestro legislador, nos plantea la interrogante de si importa una vulneración a la garantía constitucional de un justo y racional proceso, consagrada en el artículo $19 \mathrm{~N}^{\circ} 3$ inciso quinto ${ }^{1}$.

En el presente trabajo analizaremos esta novedosa institución, refiriéndonos a su origen, la tramitación del artículo específico en el Congreso Nacional y haciendo mención de su referente más inmediato; finalmente, presentaremos algunas de las problemáticas

\footnotetext{
1 Señala esta norma que "Toda sentencia de un órgano que ejerza jurisdicción debe fundarse en un proceso previo legalmente tramitado. Corresponderá al legislador establecer siempre las garantías de un procedimiento y una investigación racionales y justas".
} 
que plantea desde la perspectiva del debido proceso, concluyendo con un comentario crítico respecto de las cargas dinámicas.

\section{EL PROBLEMA DE LA CARGA DE LA PRUEBA}

La carga de la prueba constituye una regla para el sentenciador, que le indica de qué manera debe fallar cuando la falta o insuficiencia de prueba deje incierto el hecho jurídicamente relevante controvertido en el proceso $^{2}$. Así las cosas, la carga de la prueba puede definirse como una "conducta impuesta a uno o ambos litigantes, para que acrediten la verdad de los hechos enunciados por ellos"3. Al respecto, es importante destacar que la ley distribuye por anticipado esta carga, entre uno y otro litigante, en forma expresa o implíci$\mathrm{ta}^{4}$, en la medida que ambos litigantes se encuentran obligados a acreditar la veracidad de sus afirmaciones, ya que los hechos no probados se tienen por no existentes dentro del proceso. En otras palabras, puede entenderse el principio de la carga de la prueba como aquel en virtud del cual debe desecharse o no puede acogerse la pretensión de una parte si la misma no ha probado las circunstancias fácticas que sirven de sustento al precepto jurídico que han hecho valer en el juicio; es decir, en caso de no existir prueba o ser esta insuficiente, el juez aplicará las normas de la carga de la prueba y sancionará a aquella parte que no probó. En el fondo, este principio permite responder, usando una fórmula dispuesta por el legislador, la pregunta sobre a qué afirmación se le dará preferencia: si a aquella formulada por el actor o a la que ha pronunciado el demandado. Esto, atendido que el tribunal, en virtud de los principios generales que inspiran nuestro ordenamiento, se encuentra obligado a emitir un pronunciamiento que resuelva el asunto controvertido.

Ahora bien, es importante destacar el hecho que las normas sobre la carga de la prueba deben ser establecidas de manera general y no pueden deducirse del resultado del proceso singular ${ }^{5}$, de manera tal que más allá de las contingencias del litigio particular, estas normas conduzcan al juez a un resultado determinado, que sea conocido por las partes antes de trabar el proceso ${ }^{6}$. Del enunciado de esta regla, encontramos que la misma solo tendrá aplicación cuando no se acredite por las partes uno o más hechos que resultan substanciales en el proceso. Así, tras constatarse que ninguna de las hipótesis resultó probada -lo que solo podrá determinarse después de haber realizado la valoración de la prueba-, será necesario recurrir a las normas sobre carga de la prueba y entrar en una "fase de asignación de las consecuencias de la falta de prueba". Es importante señalar que se ha entendido que el principio de la carga de la prueba constituye una garantía para las partes, en el sentido que el juez no declarará producida la consecuencia establecida por la norma aplicable al caso, si en el proceso no se ha determinado el hecho condicionante de tal norma ${ }^{7}$.

\footnotetext{
2 Terrasa, Eduardo, "Cargas probatorias dinámicas", en: Activismo y garantismo, Academia Nacional de Derecho y Ciencias Sociales de Córdoba, 2009. p. 95.

${ }^{3}$ Couture, Eduardo J., Fundamentos del Derecho Procesal Civil, tercera edición, Depalma Editor, Buenos Aires, 1958 , p. 241.

${ }^{4}$ COUTURE, Eduardo J., op. cit., p. 242.

5 RosemberG, Leo, La carga de la prueba, Editorial B de F Ltda., Montevideo, 2002, p. 17.

${ }^{6}$ ROSEMBERG, Leo, op. cit., pp. 84-85.

7 TERRASA, Eduardo, op. cit., p. 104.
} 
En nuestro ordenamiento, la regla de la carga de la prueba o del onus probandi, se encuentra establecida de manera general por el artículo 1698 del Código Civil, el que dispone que "Incumbe probar las obligaciones o su extinción al que alega aquéllas o ésta", es decir, quien alega algún hecho es quien debe probarlo.

\section{LAS CARGAS PROBATORIAS DINÁMICAS}

En el procedimiento de tutela de derechos laborales se establece una regla especial sobre distribución de las cargas de la prueba, que altera la norma que consagra el citado artículo 1698 del Código Civil.

Esta regla especial está contenida en el artículo 493 del Código del Trabajo, el cual dispone que "Cuando de los antecedentes aportados por la parte denunciante resulten indicios suficientes de que se ha producido la vulneración de derechos fundamentales, corresponderá al denunciado explicar los fundamentos de las medidas adoptadas y de su proporcionalidad".

Esto es lo que se ha denominado "cargas dinámicas de la prueba" o "alivio probatorio" y consiste en la alteración de las normas sobre carga de la prueba siempre que el juez de la causa constate que se presenta en la especie el supuesto que esta norma indica, esto es, que existan indicios suficientes de que se ha producido una vulneración de una garantía fundamental.

\subsection{ORIGEN DE ESTA INSTITUCIÓN}

Para conocer los orígenes de esta disposición en nuestro ordenamiento, debemos recurrir al Mensaje del Presidente de la República ${ }^{8}$ con el que se inició el proyecto de ley que sustituyó el procedimiento laboral (Ley $N^{\circ} 20.087$ ).

En dicho mensaje se hizo expresa referencia a la necesidad de "diseñar un modelo concreto de tutela de los derechos fundamentales al interior de la empresa a través de un procedimiento especial que dé cuenta de una serie de garantías procesales conducentes a una adecuada y eficaz protección".

Más adelante, al referirse expresamente al procedimiento de tutela de derechos fundamentales, se indicó que se introducía una norma nueva en nuestro ordenamiento jurídico, consistente en "facilitar o alivianar la prueba al denunciante, cuando de sus alegaciones se desprendan indicios en orden a que se ha producido la vulneración de derechos fundamentales", lo que trae como contrapartida que el denunciado debe "justificar suficientemente, en forma objetiva y razonable, las medidas adoptadas y su proporcionalidad.

Por su parte, el profesor Ugarte ha señalado que "dado el difícil escenario probatorio que el trabajador deberá enfrentar en las denuncias por violación o lesión de derechos fundamentales, se hace absolutamente imprescindible, para otorgar una tutela efectiva de dichos derechos, la reducción de la carga probatoria en los procesos respectivos" ${ }^{\text {, }}$, agregando más adelante que la experiencia comparada demuestra la necesidad de alguna modalidad de

\footnotetext{
${ }^{8}$ Mensaje $N^{\circ} 4-350$, de 22 de septiembre de 2003.

9 UgaRTe Cataldo, José Luis, El nuevo Derecho del Trabajo, Editorial Universitaria, Santiago, 2004, p. 132.
} 
alivio o facilitación probatoria para el afectado, para poder otorgar una protección efectiva a los derechos fundamentales de los trabajadores ${ }^{10}$. En este mismo sentido, este autor ha señalado que el sistema indiciario es "una de las mayores fortalezas de la reforma procesal laboral en materia de derechos fundamentales" y corresponde "al avance principal para superar esta carrera con obstáculos que es la protección efectiva de esos derechos"11.

\subsection{TRAMitación ANTE El CONGRESO NaCiOnAL}

En el proyecto enviado por el Ejecutivo, esta norma estaba contemplada en el artículo 510, el que en su inciso primero establecía: "Cuando de las alegaciones de la parte denunciante se deduzca la existencia de indicios de que se ha producido la vulneración de derechos fundamentales, corresponderá al denunciado justificar suficientemente, en forma objetiva y razonable, las medidas adoptadas y su proporcionalidad".

En su tramitación ante el Congreso Nacional, este artículo, en su Primer Trámite Constitucional, fue aprobado por la unanimidad de los diputados presentes en la Sala. En la Comisión de Constitución, Legislación y Justicia de dicha Cámara se aprobó, por unanimidad, modificar el texto propuesto por el Ejecutivo por el siguiente: "Cuando de los antecedentes aportados por la parte denunciante resulten indicios de que se ha producido la vulneración de derechos fundamentales corresponderá al denunciado justificar las medidas adoptadas y su proporcionalidad". Mediante esta indicación, según consta en las actas de la Comisión ${ }^{12}$, se buscaba eliminar los términos o vocablos que pudieran inducir a cierta subjetividad al momento de tener por cumplidos los requisitos para presentar la denuncia.

Posteriormente, en el Segundo Informe de la Comisión de Trabajo y Seguridad Social, este artículo volvió a ser modificado, cambiándose en la parte final del mismo la expresión "justificar" por "explicar los fundamentos", siendo su redacción la siguiente: "Cuando de los antecedentes aportados por la parte denunciante resulten indicios suficientes de que se ha producido la vulneración de derechos fundamentales, corresponderá al denunciado explicar los fundamentos de las medidas adoptadas y su proporcionalidad"13.

En el Segundo Informe de la Comisión de Trabajo y Previsión Social del Senado se acordó, por la unanimidad de los miembros presentes de esa Comisión, reemplazar en este artículo las palabras "y su proporcionalidad" por "y de su proporcionalidad", con lo que se le dio la redacción definitiva a este artículo.

\subsection{LAS PROBATORIAS EN EL DERECHO COMPARADO}

\section{a) El caso español}

Dentro de los ordenamientos que contemplan una legislación similar a la introducida por la Ley $\mathrm{N}^{\circ} 20.087$ en esta materia, encontramos el caso de España, cuya normativa sirvió de modelo a la ley chilena.

10 Ugarte Cataldo, José Luis, op. cit., p. 135.

11 UgaRte CATAldo, José Luis, "La tutela de derechos fundamentales y el derecho del trabajo: de erizo a zorro", en: Revista de Derecho, vol. XX N², Valdivia, 2007, p. 65.

12 Esta indicación fue presentada por los diputados señores Juan Bustos, Jorge Burgos y Guillermo Ceroni.

${ }^{13} \mathrm{La}$ indicación que introdujo esta nueva modificación fue propuesta por los diputados señores Adriana Muñoz, Ximena Vidal, Sergio Aguiló, Patricio Cornejo, Julio Dittborn, Pedro Muñoz, Dario Paya, Edgardo Riveros, Alberto Robles, Felipe Salaberry, Rodolfo Seguel, Boris Tapia, Gonzalo Uriarte y Carlos Vilches. 
Así, la Ley de Procedimiento Laboral de España ${ }^{14}$ establece en el número dos del artículo 179 del Capítulo XI acerca "De la tutela de los derechos de libertad sindical" que "En el acto del juicio, una vez constatada la concurrencia de indicios de que se ha producido violación de la libertad sindical, corresponderá al demandado la aportación de una justificación objetiva y razonable, suficientemente probada, de las medidas adoptadas y de su proporcionalidad".

Por su parte, el artículo 181 hace aplicable este procedimiento -incluida la norma sobre carga de la prueba- a "los demás derechos fundamentales y libertades públicas, incluida la prohibición de tratamiento discriminatorio, que se susciten en el ámbito de las relaciones jurídicas atribuidas al conocimiento del orden jurisdiccional social”.

En consecuencia, es posible advertir que la norma española, cuya redacción es muy similar a la chilena, especialmente la contenida en el proyecto enviado por el Ejecutivo, resulta aplicable a la violación de la libertad sindical y a los demás derechos fundamentales y libertades públicas, semejante al catálogo de derechos que son protegidos por el procedimiento de tutela chileno, según establecen los artículos 485 y 486 del Código del Trabajo.

\section{b) Experiencia uruguaya}

En el derecho uruguayo, ha sido la jurisprudencia la que ha consagrado la institución de las "cargas dinámicas". Así, se ha entendido que el juez debe distribuir la carga de la prueba de acuerdo a la disponibilidad de los medios probatorios que tenga cada parte.

Lo anterior, en consideración al hecho que para el trabajador será más difícil poder tener acceso a las pruebas, ya que la mayoría estarán bajo la esfera de cuidado del empleador, dentro de la empresa; por lo que recae sobre este último el deber de aportar al proceso la prueba de lo que se discute, por estar en mejores condiciones de suministrarla ${ }^{15}$.

En una sentencia de la Suprema Corte de Justicia Uruguaya ${ }^{16}$, se señala que "las cargas probatorias se desplazan de actor a demandado (o viceversa) de acuerdo al que se encuentre en mejores condiciones de producirlas, dotando a la prueba de mayor flexibilidad y funcionalidad, y acentuando también el deber de colaboración que le corresponde a cada parte en el proceso, dotando a este de una concepción más solidarista”.

Esta doctrina ha sido criticada porque importa alterar las normas del onus probandi después de que ha terminado el proceso, lo que afecta el principio de contradicción, entendido como la posibilidad de las partes de intervenir y defenderse en el proceso; asimismo, se ha señalado que a través de la utilización de esta regla podría estar encubriéndose una reducción o rebaja en la necesidad de motivar las sentencias, justificando así un criterio subjetivo del juzgador ${ }^{17}$.

\footnotetext{
${ }_{14}$ Aprobada por Real Decreto Legislativo 2/1995, de 7 de abril 1995, que aprueba el Texto Refundido de la Ley de Procedimiento Laboral.

15 Mangarelli, Cristina, "La autonomía del Derecho Procesal del Trabajo y el Código General del Trabajo", en: Derecho Procesal del Trabajo, p. 46.

${ }^{16}$ RASO DELGUE, Juan "El principio protector en el proceso del trabajo", en: Derecho Procesal del Trabajo, p. 60.

17 TERRASA, Eduardo, op. cit., pp. 108-109.
} 


\section{PROBLEMAS QUE PLANTEA DESDE EL PUNTO DE VISTA DE LAS GARANTÍAS PROCESALES}

Como señalamos al inicio de este trabajo, las cargas dinámicas plantean algunos cuestionamientos desde el punto de vista del respeto de las garantías del debido proceso, que se encuentran consagradas en la Constitución Polírica del Estado, en el sentido que surge la interrogante de si la aplicación estricta de esta institución podría llevar a que dentro del procedimiento de tutela se vulneran las garantías procesales de una de las partes, en este caso, el empleador demandado.

A continuación analizaremos tres cuestiones que nos parecen relevantes respecto de esta institución, teniendo en consideración esta problemática.

\subsection{ALIGERAMIENTO PROBATORIO O INVERSIÓN DE LA CARGA DE LA PRUEBA}

Al analizar esta institución, surge la pregunta de si la norma sobre las cargas dinámicas de la prueba constituye solo un aligeramiento probatorio o si, por el contrario, representa una verdadera inversión de la carga de la prueba.

Al respecto, la postura de la doctrina es uniforme en cuanto a que no existe una inversión de la carga de la prueba ${ }^{18}$, en la medida que el empleador no debe acreditar un hecho negativo, como sería la inexistencia de la violación de un derecho fundamental.

En ese mismo sentido, en la discusión en Sala en el Senado, el senador Parra dejó constancia de que, a su entender, este precepto no altera el peso de la prueba, ya que solo se está precisando qué le corresponde probar a cada uno, de modo que no hay inversión del peso de la prueba ni se rompen los principios generales del Derecho ${ }^{19}$.

Sin perjuicio de lo anterior, el hecho dé que no se trate de una inversión de la carga de la prueba no implica que esta institución esté exenta de cuestionamientos desde la perspectiva del debido proceso, como veremos a continuación.

Por último, podemos afirmar que aunque no existe una inversión de la carga de la prueba, igualmente el estándar probatorio para el empleador será más alto, en la medida que deberá probar la legitimidad de la motivación de la decisión que dio origen al proceso, en tanto que el trabajador solo deberá demostrar la existencia de indicios suficientes, cuestión a las que nos referiremos en el punto siguiente.

\section{2. ¿QUÉ SE ENTIENDE POR INDICIOS SUFICIENTES?}

En virtud de la norma contemplada en el artículo 493 del Código del Trabajo, el denunciante debe aportar antecedentes de los cuales se puedan desprender indicios suficientes, que permitan al juez considerar que se ha producido la vulneración de un derecho fundamental, para que tenga aplicación la norma de las cargas dinámicas.

Cabe preguntarse, entonces, cuál es el alcance de la frase "indicios suficientes", la que no aparece claramente definida por el legislador, pese a que constituye la "puerta de

18 Walter Diaz, Rodolfo, Lanata Fuenzalida, Gabriela, Régimen legal del nuevo proceso laboral chileno, Editorial LexisNexis, Santiago, 2007, p. 171.

${ }^{19}$ Historia de la Ley $\mathrm{N}^{\circ} 20.087$, p. 653. 
entrada" a este sistema de "aligeramiento probatorio". Sobre este aspecto pueden existir, a. lo menos, dos interpretaciones distintas, a saber:

a) Entender que corresponden a algo más que meras alegaciones, pero menos que una prueba, lo que implica que el demandante deberá aportar elementos que permitan suponer o sospechar la existencia de una vulneración a un derecho fundamental, sin necesidad de acreditar el hecho en cuestión.

Es en este sentido que parece expresarse el Mensaje Presidencial al referirse al procedimiento de tutela, cuando afirma que "al trabajador le basta con que de sus alegaciones se desprendan 'indicios', es decir, señales o evidencias que den cuenta de un hecho oculto (violación de un derecho fundamental)" 20 .

Por otra parte, se ha señalado que el nuevo procedimiento laboral ha buscado facilitar o alivianar la prueba al denunciante, por lo que únicamente se requiere "que en sus alegaciones existan indicios en orden a que se ha producido la vulneración de derechos fundamentales" 21 .

Se ha dicho también, que lo que se debe probar es la "existencia de indicios que hagan verosímil la existencia de la lesión"; indicios estos que "han de generar en el juzgador, al menos la sospecha fundada de que ha existido discriminación" 22 .

b) Interpretarlo en el mismo sentido que las normas de las presunciones, lo que implica que el demandante debe acompañar elementos probatorios.

Este es el análisis del profesor Gamonal ${ }^{23}$, quien define la prueba indiciaria como "un estándar probatorio que exige una prueba mínima de la vulneración de un derecho fundamental del trabajador subordinado para que sea el empleador quien deba justificar la licitud de su actuación”. A continuación, señala que los estándares de prueba son "los criterios que indican cuándo se ha conseguido la prueba de un hecho", haciendo presente que los mismos varían en función de distintas consideraciones (estructura del contexto procesal, finalidades que se le asignan al proceso, valores éticos-políticos prioritarios, regulación de las cargas probatorias) y que en materia laboral considera "siempre la posición de debilidad del trabajador y de subordinación jurídica al poder del empleador".

Concluye, sosteniendo que la valoración del indicio laboral debe ser más exigente con la hipótesis que lo da por no probado que con la que lo acredita como factible, y establece como estándar probatorio en esta materia, el siguiente: "Si es plausible el indicio presentado y probado por el trabajador de forma tal que se hace necesario que el empleador justifique su conducta al tenor del artículo 485, el juez debiera dar por probado el indicio". Esta plausibilidad, nos dice el académico, será determinada por el juez teniendo en consideración el número (dos o más), la concordancia (deben coincidir en una misma dirección), la plausibilidad (hechos de cada indicio deben estar acreditados) y la coherencia (inferencias racionales que se correspondan con el buen sentido y la lógica).

\footnotetext{
${ }^{20}$ Historia de la Ley $\mathrm{N}^{\circ} 20.087$, p. 26.

21 Walter DfaZ, Rodolfo; LANATA FuenZaLIDA, Gabriela, op. cit, p. 169.

22 Ugarte Cataldo, José Luis, El nuevo Derecho... (n. 9), pp. 132-133.

23 Gamonal Contreras, Sergio, El procedimiento de Tutela de Derechos Laborales, segunda edición, Editorial LegalPublishing, Santiago, 2008, pp. 27-32.
} 
En nuestra opinión, esta segunda postura es la única que se aviene con los principios del debido proceso, toda vez que si se entiende que la exigencia es solo de aportar meros antecedentes, se rompe con el principio de igualdad de las partes y de bilateralidad de la audiencia, entendido como la posibilidad de que "ambas partes tengan las mismas posibilidades y cargas de ataque y de defensa, así como en orden a las alegaciones, pruebas e impugnaciones" 24 , en la medida que se impone al empleador una carga mayor que al trabajador demandante, lo que importa una vulneración de la garantía constitucional de un proceso racional y justo.

Por otra parte, es posible sostener que el hecho que en el Congreso Nacional se haya modificado esta norma, exigiéndose "antecedentes" y no solo "alegaciones" como en el proyecto del Ejecutivo, refuerza la tesis en el sentido que lo que se exige es la existencia de elementos probatorios, más aún cuando dicha modificación tuvo por objeto eliminar los elementos subjetivos de la norma, como lo serían las "meras sospechas". Sin embargo, no podemos dejar de hacer presente que en la historia de la ley no existe una referencia clara a este aspecto ni se encuentran otros elementos que sirvan de sustento a esta postura.

\subsection{DEBER DE COMUNICAR AL DEMANDADO LA EXISTENCIA DEL ALIGERAMIENTO PROBATORIO.}

En el Código del Trabajo no existe un mandato al juez para que advierta a la parte demandada el hecho de que se han presentado "indicios suficientes" por parte del trabajador denunciante, lo que conlleva, de acuerdo al referido artículo 493 del Código del Trabajo, la necesidad de que el empleador acredite los fundamentos y proporcionalidad de la medida adoptada.

Este es un aspecto relevante a la luz del debido proceso ${ }^{25}$. En efecto, no se trata de que el demandado conozca la norma en cuestión (cosa que por lo demás debemos suponer, en virtud de lo dispuesto en el artículo 8 del Código Civil), sino de que el empleador sepa oportunamente que el juez de la causa considera que existen "indicios suficientes", de modo que pueda ejercer su derecho a defensa y se encuentre en condiciones de aportar los medios de prueba que estime pertinentes para probar la motivación legitima de su actuación ${ }^{26}$.

Lo anterior, debemos vincularlo con el momento en el cual el tribunal llega a la conclusión de que se han presentado indicios suficientes. De acuerdo con las normas generales de la carga de la prueba -que analizamos brevemente en el acápite 2 precedente-, esta regla opera en la etapa de la dictación de la sentencia, después de que se ha realizado la ponderación de la prueba, al constatar que las probanzas rendidas resultan insuficientes para dar por acreditado un determinado hecho.

Esto nos plantea la imposibilidad de que se pueda advertir oportunamente al demandado-empleador de que se hará uso de la regla de las cargas probatorias dinámicas, ya

\footnotetext{
24 Walter Dlaz, Rodolfo; Lanata Fuenzalida, Gabriela, op. cit, p. 41; Ugarte CaTaldo, José Luis, El nuevo Derecho... (n. 9), p. 133; UGarTe CaTALdo, José Luis, "La tutela... (n. 11), p. 64.

25 A esto parece apuntar el profesor Orellana, en: ORELlANA TORREs, Fernando, Comentarios al nuevo proceso laboral, segunda edición, Librotecnia, Santiago, 2008, p. 270.

26 En este sentido, PALAVECINO CÁCERES, Claudio, "La carga de la prueba en el procedimiento de tutela laboral". Disponible en: http://productos2.legalpublishing.cl/newletter/juridico/reportejuridico-759/content-5827.html (Fecha de consulta: 11 de septiembre de 2009).
} 
que -al menos en principio- el sentenciador no podría saber que necesitará acudir a esta regla antes de la etapa de fallo, ya que, según hemos señalado, esta norma solo tendrá aplicación en el caso de no encontrarse probado suficientemente el hecho controvertido.

Por lo tanto, si el demandado no puede saber si el juez va a hacer uso o no de esta atribución, estimamos que se encuentra en una situación de desigualdad respecto del denunciante, en la medida que siempre se encontrará obligado a acreditar más allá de sus propias afirmaciones (que es la regla general en materia probatoria), por la posibilidad de que se recurra al aligeramiento probatorio. En consecuencia, su carga probatoria será superior a la del actor, quien se limitará a crear una sospecha de una vulneración o, según nuestra postura, a demostrar el hecho indicador o indicio.

Distinto sería si el juez realizará una ponderación de los antecedentes aportados por el denunciante al momento de fijar los hechos sobre los cuales deberá recaer la prueba, puesto que en ese caso podría advertir al demandado que se encuentran presentes los requisitos del artículo 493 del Código del Trabajo y, por tanto, de su obligación de acreditar la legitimidad de su decisión.

Sin embargo, estimamos que al no existir una norma que expresamente establezca la necesidad de realizar esta ponderación antes de que se abra la etapa probatoria, no solo no existe una obligación para el juez respecto de hacer esta advertencia, sino que, además, al hacerlo podría estar adelantando su sentencia y con ello incurrir en una causal de implicancia ${ }^{27}$.

Conjuntamente con lo anterior, debe tenerse en consideración que no necesariamente será el mismo juez el que conduzca la Audiencia Preparatoria (donde se fijarán los hechos a probar y los medios de prueba ofrecidos por las parte) y aquel que esté a cargo de la Audiencia de Juicio y deba, por lo tanto, dictar sentencia con sujeción a las probanzas aportadas por las partes o, en caso de ser insuficientes las mismas, de acuerdo con las normas de la carga de la prueba y, en este caso particular, de las cargas dinámicas, por lo que podría suceder que existieran criterios diversos entre estos jueces, con lo cual podría volver a presentarse el problema de la falta de advertencia.

\section{CONCLUSIONES}

Como hemos visto a lo largo del presente trabajo, la institución de las cargas dinámicas plantea algunos problemas desde la perspectiva del debido proceso, en este caso, como garantía constitucional que ampara al empleador-denunciado en un procedimiento de tutela laboral.

Lo anterior, en la medida que rompe con el principio de igualdad procesal de las partes, al imponer al empleador un estándar probatorio mayor al que soporta el trabajador -especialmente si se considera que este únicamente debe provocar una sospecha en el juzgador-; así como vulnera su derecho a la debida defensa, en cuanto no se le advierte

\footnotetext{
${ }_{27}$ Podría salvarse este obstáculo estableciéndose una norma análoga a la de la conciliación, de manera tal que las opiniones que se emitieran para hacer presente la posibilidad de aplicar la disposición en comento, no pudieran ser consideradas como causal de inhabilitación.
} 
oportunamente de la posibilidad de que se altere la regla de la carga de la prueba y se vea obligado a acreditar una cuestión diversa a los hechos enunciados en su defensa, en la medida que el juez solo recurrirá a la regla de las cargas dinámicas al momento de dictar sentencia.

Esto nos lleva a concluir que este instituto, de la forma como aparece regulado actualmente, pone al demandado en una posición de disparidad respecto del actor, lo que se contradice con la garantía de un debido proceso, entendido como un procedimiento justo y racional para todas las partes involucradas.

En consecuencia, resulta imperioso modificar esta norma y establecer una regla clara que ponga término a la incertidumbre procesal para la parte demanda y que, por sobre toda otra consideración, importe el respeto efectivo de su derecho a la defensa jurídica, ya que la garantía del debido proceso se encuentra establecida en beneficio de ambas partes y no respecto de solo una de ellas como resulta de la norma actual, por más débil que se la considere.

\section{BIBLIOGRAFÍA}

Couture, Eduardo J., Fundamentos del Derecho Procesal Civil, tercera edición, Depalma Editor, Buenos Aịres, 1958, 524 pp.

Gamonal Contreras, Sergio, El procedimiento de Tutela de Derechos Laborales, Segunda Edición, Legal Publishing, Santiago, 2008, 92 pp.

Mangarelli, Cristina, "La autonomía del Derecho Procesal del Trabajo y el Código General del Trabajo", en: Derecho Procesal del Trabajo, pp. 35-48.

OrellaNA TORRES, Fernando, Comentarios al nuevo proceso laboral, segunda edición, Librotecnia, Santiago, 2008, 333 pp.

PALAVECINo CACERES, Claudio, "La carga de la prueba en el procedimiento de tutela laboral". Disponible en: http://productos2.legalpublishing.cl/newletter/juridico/reportejuridico-759/content-5827.html (Fecha de consulta: 11 de septiembre de 2009).

RASO Delgue, Juan "El principio protector en el proceso del trabajo", en: Derecho Procesal del Trabajo, pp. 49-62.

Rosemberg, Leo, La carga de la prueba, Editorial B de F Ltda., Montevideo, 2002.

TERraSA, Eduardo, "Cargas probatorias dinámicas", en: Activismo y garantismo, Academia Nacional de Derecho y Ciencias Sociales de Córdoba, 2009, pp. 95-120.

UGarte CATALDO, José Luis, "La turela de derechos fundamentales y el derecho del trabajo: de erizo a zorro", en: Revista de Derecho, vol. XX N² 2, Valdivia, 2007, pp. 49-67.

Ugarte CaTALDo, José Luis, El nuevo Derecho del Trabajo, Editorial Universitaria, Santiago, 2004, 183 pp.

Walter Dfaz, Rodolfo; Lanata Fuenzalida, Gabriela, Régimen legal del nuevo proceso laboral chileno, LexisNexis, Santiago, 2007, 237 pp. 